11 Mosca L, Collins P, Herrington DM, et al. Hormone replacement therapy and cardiovascular disease: a statement for healthcare professionals from the American Heart Association. Circulation 2001; 104: 499-503.

12 Shumaker SA, Legault C, Rapp SR, et al Estrogen plus progestin and the incidence of dementia and mild cognitive impairment in postmenopausal women: the Women's Health Initiative Memory Study: a randomized controlled study. JAMA 2003; 289: 2651-2662.

13 Weiderpass E, Adami HO, Baron JA. Risk of endometrial cancer following estrogen replacement with and without progestins. J Natl Cancer Inst 1999; 91: 1131-1137.

14 Sturdee DW, Ulrich LG, Barlow DH, et al. The endometrial response to sequential and continuous combined oestrogen-progestogen replacement therapy. Br J Obstet Gynaecol 2000; 197: 1392-1400.

15 Scarabin PY, Olger E, Plu-Bureau G. Differential association of oral and transdermal oestrogen replacement therapy with venous thromboembolism risk. Lancet 2003; 362: 428-432.

16 Chu MC, Rath KM, Huie J, Taylor HS. Elevated basal FSH in normal cycling women is associated with unfavourable lipid levels and increased cardiovascular risk. Hum Reprod 2003; 18: 1570-1573.

17 Stevenson J. Long term effects of hormone replacement therapy. Lancet 2003; 361(9353): 253-254.

18 Women's Health Initiative (WHI) website. http://www.whi.org

19 HRT: update on the risk of breast cancer and long-term safety. Current Problems in Pharmacovigilance September 2003; 29: 1-3. http://www.mca.gov.uk

20 New product information for hormone replacement therapy. Current Problems in Pharmacovigilance April 2002; 28: 1-2. http:// www.mca.gov.uk

21 Pitkin J, Rees MCP, Gray S, et al. Managing the menopause. British Menopause Society Council consensus statement on hormone replacement therapy. J Br Menopause Soc 2003; 9(3): 129-131.

22 Panay N, Studd JWW. Progestogen intolerance and compliance with hormone replacement therapy in menopausal women. Hum Reprod Update 1997; 3: 159-171.

23 Lagro-Janssen T, Rosser W, Van Weel C. Breast cancer and hormone replacement therapy: up to general practice to pick up the pieces. Lancet 2003; 362: 414-415.

\title{
OVERVIEW
}

\section{The laboratory diagnosis of common genital viral infections}

\author{
Edward L Chan, PhD, FCCM, Director of Clinical Microbiology, Department of Pathology, Baptist Medical Center-Montclair, \\ Birmingham, AL, USA; Margaret A Kingston, MRCP, DFFP, Consultant in Genitourinary Medicine, Manchester Centre for \\ Sexual Health and Manchester Children's University Hospitals NHS Trust, Manchester Royal Infirmary, Manchester, UK; \\ Elizabeth M Carlin, DFFP, FRCP, Consultant in Genitourinary Medicine, Department of Genitourinary Medicine, Nottingham \\ City Hospital NHS Trust, Nottingham, UK
}

Correspondence: Dr Edward L Chan, Department of Pathology, Baptist Medical Center-Montclair, Birmingham, AL 35213-1984, USA. E-mail: Edward.Chan@BHSALA.com

(Accepted 19 October 2003)

Journal of Family Planning and Reproductive Health Care 2004; 30(1): 24-25

\section{Background: epidemiology and clinical features}

The incidence of viral genital infections has risen considerably in recent years. Genital warts, a clinical manifestation of genital human papilloma virus (HPV) infection, is the commonest sexually transmitted infection (STI) in the UK and comprised $10 \%$ of all diagnoses made in genitourinary medicine (GUM) clinics in 2002. ${ }^{1}$ There are over 90 subtypes of HPV, some are 'high risk' with oncogenic potential, the most frequently occurring of these are types 16, 18 and 32. However, the subtypes that result in the vast majority of genital warts are the 'low risk' types 6 and 11 . Subclinical infection is extremely common, with up to $46 \%$ of sexually active young women found to be positive for HPV by polymerase chain reaction (PCR) DNA amplification testing of cervical and vulval specimens. ${ }^{2}$ In younger women most HPV infections are transient and resolve spontaneously, but in older women they may be more persistent. ${ }^{3,4}$ Clinically apparent genital HPV infection most often appears as single or multiple warty lesions in the genital areas. Another common cause of small, fleshy growths in the genital area is molluscum contagiosum, a pox virus. These can have a similar appearance to warts but the lesions have a characteristic umbilicated centre. In genital areas they are usually sexually transmitted. However, in children they are commonly observed on non-genital sites such as the hands, where they are not sexually transmitted, and in immunosuppressed adults they may cause problematic facial lesions.

Herpes simplex virus (HSV) infection is the commonest ulcerative STI. In common with HPV infection, HSV infection is frequently subclinical, but when symptoms do occur they include painful blisters or ulcers in the genital area with or without regional lymphadenopathy and systemic symptoms. Subclinical shedding of the virus from genital skin occurs even in the absence of symptoms ${ }^{5}$ and plays a major role in transmission of the virus. Genital herpes is the result of infection with HSV type 2 or, with increasing frequency, HSV type 1 (the usual cause of oral herpes, or cold sores), which now accounts for nearly $50 \%$ of all cases of genital HSV infection. Between 1972 and 2002, the number of genital HSV diagnoses made at GUM clinics increased two-fold in women and nine-fold in men, with the highest rates of infection observed in those aged 20-24 years. ${ }^{1}$

\section{Diagnosis of genital HPV infection}

Diagnosis of HPV infection is usually by clinical observation, but if in doubt a biopsy may be taken for histology. For the purposes of clinical research HPV identification may be undertaken, but this is not usually available or performed in routine clinical practice.

HPV cannot be grown in vitro and so is usually detected by nucleic acid amplification tests. As HPV is an intracellular organism cells may be exfoliated by brushing, or alternatively by biopsy and placed in transport medium. Dot blot assay is a simple method of detecting viral nucleic acid from cells with labelled probes binding to the DNA. Southern blot technique involves separation of HPV DNA fragments extracted from cells by gel electrophoresis followed by hybridisation with labelled probes on a nitrocellulose membrane. In situ hybridisation is usually performed on tissue sections using DNA probes for hybridisation. PCR and hybrid capture II are further methods of nucleic acid detection, and hybrid capture has been successfully used with urine specimens. ${ }^{6}$ Serological tests have no value in clinical practice or screening. 
Diagnosis of molluscum contagiosum

This is usually based on the characteristic appearance, but if there is any doubt the core of the lesion can be sent for evaluation by electron microscopy, and the poxvirus particles observed. Occasionally histology is performed, particularly for large lesions, and typical findings are of a keratotic core of infected epidermal cells containing large viral inclusions. ${ }^{7}$

\section{Diagnosis of HSV infection \\ Specimen collection}

As vesicular fluid may contain up to $10^{9}$ viral particles per millilitre, taking a sample at this stage of infection gives the best chance of detecting the virus. In one study the culture yield at different stages of infection was vesicle/pustule $90 \%$, ulcer $70 \%$ and crusting lesion $27 \% .^{8}$ Moistening the swab with transport media prior to sampling makes the sample easier to take and less uncomfortable. The swab should be placed in transport media, and for techniques such as culture a cold chain needs to be maintained during rapid transportation to the laboratory. As the lesions are often exquisitely tender, care should be taken not to cause undue discomfort to the patient during sampling.

\section{Cell culture}

This remains the 'gold standard' method of HSV detection. Cytopathic effect (CPE) on cell culture is often demonstrated in 24-48 hours, though it may take up to 10 days if the viral number is low. CPE is then confirmed using type-specific antibodies, which permits simultaneous typing of the virus.

\section{$P C R$}

As yet there is no commercially available assay, so currently the use of this test is mainly limited to research where it has demonstrated high sensitivity, rapid turnaround of results and also allows viral typing. As with any PCR test, controls for cross contamination are important.

\section{Other techniques}

Direct immunofluorescence (DFA) and enzyme immunoassay (EIA) are antigen-antibody assays that have the advantage of detecting living and dead viral particles. The advantage of EIA over DFA is that it can be used in a high-volume laboratory to process large numbers of samples with a quick turnaround time. Though highly specific, the sensitivity of these assays is only around $60-70 \%$.
A serology test will not be the first choice for the diagnosis of genital HSV infection. Caution is needed in interpreting the results and the clinical use of these tests has not been fully evaluated, so virus detection remains the method of diagnostic choice. Serology may have a role in experienced hands in the management of ulceration of unknown cause, and in potentially discordant couples, particularly during pregnancy.

\section{Summary}

The common viral genital infections, HPV and HSV, have increased in prevalence in recent years, most often affecting young, sexually active people. They are frequently asymptomatic, with transmission often occurring during this time, and this fact is of crucial importance when counselling affected individuals. Diagnosis of HPV infection is usually clinical, though HPV detection techniques are used for clinical research. Similarly, molluscum contagiosum, another common viral skin infection affecting the genital areas in adults, is usually diagnosed clinically by its characteristic umbilicated appearance. The diagnosis of genital HSV infection is usually made clinically and confirmed by taking and processing a swab correctly for cell culture. Although not commercially available, PCR is an important development offering improved sensitivity and is likely to be used more frequently in the future.

Statements on funding and competing interests

Funding. None identified.

Competing interests. None identified.

References

1 Genital warts: epidemiological data. http://www.hpa.org.uk/ infections/topics.

2 Bauer, HM, Greer CE, Chambers JC, et al. Genital human papilloma virus infection in female university students as determined by a PCRbased method. J Am Med Assoc 1991; 154: 333-334.

3 Ho G, Bierman R, Beardsley L, et al. Natural history of cervicovaginal papillomavirus infection in young women. $N$ Engl $J$ Med 1998; 338: 423-428.

4 Hildesheim A, Schiffman MH, Gravitt PE, et al. Persistence of typespecific human papillomavirus infection among cytologically normal women. J Infect Dis 1994; 169: 235-240.

5 Wald A, Zeh J, Selke S, et al. Reactivation of genital herpes simplex virus type 2 infection in asymptomatic seropositive persons. $N$ Engl $J$ Med 2000; 342: 844-850.

6 Jacobson DL, Womack SD, Peralta L, et al. Concordance of human papillomavirus in the cervix and urine among inner city adolescents. Pediatr Infect Dis J 2000; 19: 722-728.

7 Stevens A, Lowe J. Dermatopathology. In: Pathology, CV Mosby 1995; 449 .

8 Scoular A, Gillespie G, Carman WF. Polymerase chain reaction for diagnosis of genital herpes in a genitourinary medicine clinic. Sex Transm Infect 2002; 78: 21-25.

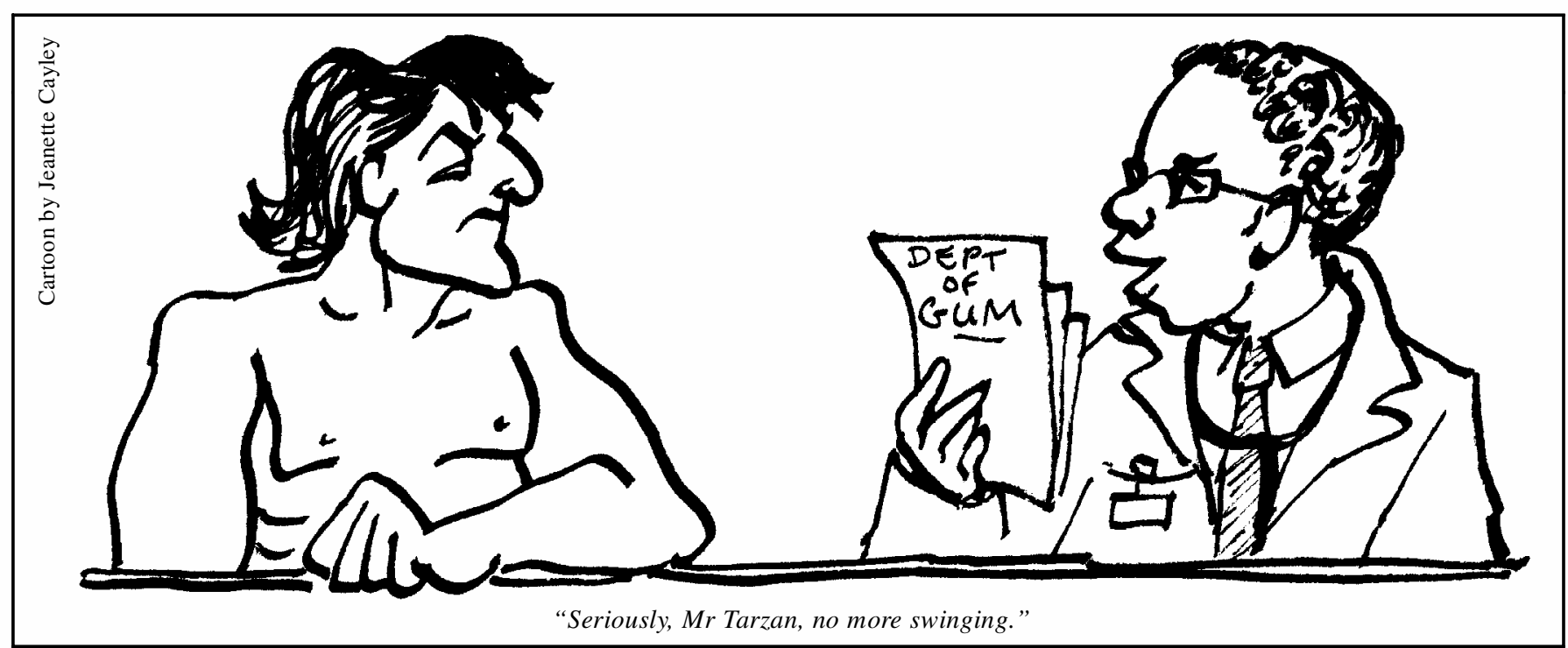

